\title{
Comparative Evaluation of Anti-Inflammatory Activity of Curcuminoids, Turmerones, and Aqueous Extract of Curcuma longa
}

\author{
Ashish Subhash Bagad, Joshua Allan Joseph, Natarajan Bhaskaran, and Amit Agarwal \\ RङD Centre, Natural Remedies, Plot No. 5B, Veerasandra Indl. Area, 19th K.M. Stone, Hosur Road, Electronic City, \\ Bangalore, Karnataka 560 100, India \\ Correspondence should be addressed to Joshua Allan Joseph; joshua@naturalremedy.com \\ Received 10 August 2013; Revised 5 November 2013; Accepted 18 November 2013 \\ Academic Editor: Antonio Ferrer-Montiel \\ Copyright (C) 2013 Ashish Subhash Bagad et al. This is an open access article distributed under the Creative Commons Attribution \\ License, which permits unrestricted use, distribution, and reproduction in any medium, provided the original work is properly \\ cited. \\ Curcuma longa is widely known for its anti-inflammatory activity in traditional system of medicine for centuries and has been \\ scientifically validated extensively. The present study was conducted to evaluate the anti-inflammatory activity of curcuminoids and \\ oil-free aqueous extract (COFAE) of $C$. longa and compare it with that of curcuminoids and turmerones (volatile oil), the bioactive \\ components of $C$. longa that are proven for the anti-inflammatory potential. The activity against inflammation was evaluated in \\ xylene-induced ear edema, cotton pellet granuloma models in albino Swiss mice and albino Wistar rats, respectively. The results \\ showed that COFAE of $C$. longa at three dose levels significantly $(P \leq 0.05)$ inhibited inflammation in both models, as evidenced \\ by reduction in ear weight and decrease in wet as well as dry weights of cotton pellets, when compared to the vehicle control. The \\ COFAE of $C$. longa showed considerable anti-inflammatory effects against acute and chronic inflammation and the effects were \\ comparable to those of curcuminoids and turmerones.
}

\section{Introduction}

Inflammation is a transitory biological response of the tissues to harmful stimuli such as injury, exogenous and endogenous antigens, intended to clear or eliminate the stimulus and repair the injured tissue ultimately resulting in regeneration and returning to homeostasis [1]. Though inflammation is a positive defense mechanism of the body, dysregulated and prolonged inflammatory reaction has been well recognized as underlying cause for several disorders, namely, diabetes, allergies, atherosclerosis, obesity, cancer, and pain. Moreover, inflammation dysfunction leading to chronic diseases is contributing to increased health care cost to the society $[2,3]$.

Nonsteroidal anti-inflammatory drugs (NSAIDs), steroids, and immunosuppressant drugs that have been used conventionally against all forms of inflammatory conditions [4] are associated with adverse effects like ulceration, per- foration, gastric irritation, haematochezia [5], angioedema, hepatic failure, headache, hemolytic anemia, hyperglycemia, osteoporosis, immunodeficiency-related problems, and others [6]. Considering these potential adverse effects of these drugs and their limited ability to provide long-term remission, complementary and alternative medicinal products that are generally considered safe are continuously being explored for their anti-inflammatory potential [7].

Curcuma longa Linn. (Turmeric) belonging to Zingiberaceae family has been widely used as medicine, condiment, and cosmetic worldwide $[8,9]$ and valued as a functional food because of its health promoting potentials [10]. The rhizome of $C$. longa, a traditional medicine used for centuries in the Indian subcontinent, has been scientifically validated for its antioxidant [11], antimicrobial [12], antiarthritic [13], anticancer [14], carminative, stomachic, tonic, analgesic, hemostatic $[15,16]$ and anti-inflammatory activities 
[17]. Most of the studies performed on C. longa focused on curcuminoids components which comprised curcumin, demethoxycurcumin, and bisdemethoxycurcumin [18] and the anti-inflammatory effect of $C$. longa was attributed majorly to curcumin [17] acting through the suppression of NF-kappaB and COX-2 activation. The other bioactive components of turmeric, namely, volatile oils, especially turmerones, are also reported to have immunomodulatory and anti-inflammatory activities in few of the studies $[19,20]$. Albeit few reports on antiproliferative [21, 22], antidiabetic [23] activities of curcumin-free extract of turmeric are available, anti-inflammatory potential of the same is hardly ever reported.

Curcuminoids and turmerones extracted from C. longa are usually used for medicinal as well as cosmetic purposes and indeed the curcuminoids and turmerone-free component of turmeric are often not used in the preparation of turmeric formulations as hardly any information is available on their bioactivity. Moreover, curcuminoids and oil-free aqueous extract of $C$. longa, a spent extract, have not been yet explored for the anti-inflammatory potential. Therefore, the present study was designed to evaluate the anti-inflammatory activity of COFAE of C. longa in suitable in vivo models, keeping in view that it may help in advancing the scientific understanding and ascertaining a better utility of the extract. The study also focused on comparing the effect of COFAE of $C$. longa with that of curcuminoids and turmerones, the bioactive components of $C$. longa that are already proven for the anti-inflammatory potential.

\section{Materials and Methods}

2.1. Animals. Experiments were performed on male albino Swiss mice and albino Wistar rats of either sex bred and reared at Central Animal Facility, Research and Development Centre, Natural Remedies, Bangalore, India. The animals were housed under standard laboratory conditions of $12 \mathrm{~h} / 12 \mathrm{~h}$ light/dark cycle at $20-24^{\circ} \mathrm{C}$ and $30-70 \%$ humidity and were provided free access to pelleted rodent feed $(\mathrm{M} / \mathrm{s}$ Gold Mohur Foods and Feeds, Bangalore, India) and UV purified water. The animal studies were approved by the Institutional Animal Ethics Committee.

2.2. Drugs and Chemicals. Dexamethasone and diclofenac sodium were obtained from Cadila Healthcare (India) and Novartis Pharma (India) respectively. Xylene was obtained from Leonid Chemicals (India).

\subsection{Plant Materials}

2.3.1. Curcuminoids. Rhizomes of C. longa L. were procured from local market at Bangalore, India, and were authenticated at the National Institute of Science Communication and Information Resources (NISCAIR). A voucher specimen (no. 653) was deposited in the Pharmacognosy Department of R\&D Centre, Natural Remedies, Bangalore, India. Coarse ground rhizomes $(2 \mathrm{~kg})$ were refluxed with ethyl acetate $(8 \mathrm{~L})$ for $3 \mathrm{~h}$ on a water bath and filtered. The extraction procedure was repeated two more times. The filtered extract solutions obtained in each step were combined and concentrated by distillation under vacuum at less than $50^{\circ} \mathrm{C}$ to get a thick paste. The latter was further stirred with petroleum ether $(1: 3$, 3 times) at room temperature and the insoluble matter was crystallized using isopropyl alcohol to yield yellow powder of curcuminoids (50 g).

2.3.2. COFAE of C. longa. The marc (powdered rhizomes obtained after ethyl acetate extraction) was then extracted with water ( $8 \mathrm{~L}, 3$ times) at $100^{\circ} \mathrm{C}$ for 3 hours and filtered. The liquid extracts from three extraction washes were combined and concentrated by distillation under vacuum at $70^{\circ} \mathrm{C}$ to yield a solution having $20 \% \mathrm{w} / \mathrm{w}$ solids. The concentrated solution was then spray-dried to obtain a free flowing powder (180 g).

2.3.3. Oil of C. longa. Coarse ground rhizomes of C. longa $(5 \mathrm{~kg})$ were suspended in water $(100 \mathrm{~L})$ and subjected to steam distillation. The oil layer was separated and passed through anhydrous sodium sulphate to get clear oil $(26 \mathrm{~mL})$.

2.4. Treatments Schedule. Seventy-two male albino Swiss mice (xylene-induced ear edema model) and seventy-two albino Wistar rats of either sex (cotton pellet granuloma model) were randomly allotted to twelve groups, each consisting of six animals. In xylene-induced ear edema model, the control group received vehicle (water, $10 \mathrm{~mL} / \mathrm{kg}$ ); two other groups of mice were treated with 0.5 and $50 \mathrm{mg} / \mathrm{kg}$ body weight of dexamethasone and diclofenac, respectively, as reference standard drugs. The remaining nine groups received three dose levels of curcuminoids, turmerones, and COFAE, respectively. Curcuminoids were administered at 20, 60 , and $180 \mathrm{mg} / \mathrm{kg}$ mice body weight, whereas turmerones were administered at $0.05,0.1$, and $0.25 \mathrm{~mL} / \mathrm{kg}$, while COFAE at 90,180 , and $360 \mathrm{mg} / \mathrm{kg}$ mice body weight were administered.

In cotton pellet granuloma model, the control group received vehicle (water, $10 \mathrm{~mL} / \mathrm{kg}$ ); two other groups of rats were treated with 0.5 and $5 \mathrm{mg} / \mathrm{kg}$ body weight of dexamethasone and diclofenac, respectively, as reference standard drugs. Curcuminoids were administered at 5, 25, and $125 \mathrm{mg} / \mathrm{kg}$ rat body weight, whereas turmerones were administered at 0.05 , 0.1 and $0.15 \mathrm{~mL} / \mathrm{kg}$, while COFAE at 45,90 , and $180 \mathrm{mg} / \mathrm{kg}$ rat body weight were administered to nine groups of rats. Vehicle/reference drugs/test substances were administered by gavage using feeding needle.

2.5. Xylene-Induced Ear Edema. The xylene-induced ear edema test was performed as previously described [24]. Male albino Swiss mice weighing 20-30 g (6-8 weeks) were administered with vehicle/drugs/test substances orally $1 \mathrm{~h}$ prior to the xylene $(50 \mu \mathrm{L})$ application to the anterior and posterior surfaces of the right ear topically, while left ear served as control. After $4 \mathrm{~h}$ of xylene application, animal was sacrificed; both ears were removed and ear discs of $6 \mathrm{~mm}$ diameter were punched out and weighed. The average weight 
difference between the right and left ear was taken as the measure for inflammatory response.

2.6. Cotton Pellet-Induced Granuloma. Albino Wistar rats weighing 150-180 g (6-8 weeks) were completely deprived of food for $1 \mathrm{~h}$ before the vehicle/drugs/test substances administration but had free access to water. Rats were anaesthetized and sterile cotton pellets $(10 \mathrm{mg})$ were implanted subcutaneously in axilla and groin regions of rats. The entire procedure was carried out aseptically. Rats were administered vehicle/drug/test substances once daily orally for seven consecutive days. On the eighth day, cotton pellets were meticulously dissected out and dried at $60^{\circ} \mathrm{C}$ for $24 \mathrm{~h}$. The dry and wet weights of cotton pellet were measured [25]. The percentage inhibition was calculated by using the following formula:

$$
\text { Percentage inhibition }=\frac{(\text { Control }- \text { Treated })}{\text { Control }} \times 100 .
$$

2.7. Statistical Analysis. All the values were expressed as mean \pm SEM. The data were analyzed using one-way ANOVA followed by post hoc Dunnett's test. Statistical significance was set at $P \leq 0.05$.

\section{Results}

3.1. Xylene-Induced Ear Edema. The average weight of the ears and the percentage inhibition of inflammatory response are presented in Figure 1 and Table 1, respectively. Topical application of xylene caused an evident increase in weight of the right ear when compared to the control left ear in the vehicle control group, whereas the reference drugs, dexamethasone $(0.5 \mathrm{mg} / \mathrm{kg})$ and diclofenac $(50 \mathrm{mg} / \mathrm{kg})$, that served as positive controls showed significant reduction in the average ear weight in comparison to the vehicle control. Likewise, COFAE of C. longa at all the tested doses (90, 180, and $360 \mathrm{mg} / \mathrm{kg}$ b.w.), turmerones at the doses of 0.05 and $0.1 \mathrm{~mL} / \mathrm{kg}$ b.w. and curcuminoids at dose levels of 20,60, and $180 \mathrm{mg} / \mathrm{kg}$ b.w., revealed significant reduction in the average ear weight as compared to vehicle control group.

3.2. Cotton Pellet-Induced Granuloma. The average wet and dry weights of cotton pellets along with percentage inhibition are summarized in Table 2. The vehicle control group showed marked inflammatory response manifested as increase in the wet and dry weights of the pellets. The positive controls, namely, dexamethasone and diclofenac, showed significant reduction in both wet and dry weights of the cotton pellets as compared to the vehicle control. Meanwhile, COFAE of C. longa at doses of 45,90 , and $180 \mathrm{mg} / \mathrm{kg}$ exhibited significant reduction in wet and dry weights of the cotton pellets, as compared to the vehicle control. The percentage inhibition in case of wet weight of pellets which was considered a measure of inhibition of transudative and exudative phases of inflammation was found to be $44.2,42.6$, and 36.9 , respectively. And the percentage inhibition in case of dry weight of pellets which was considered a measure of inhibition of proliferative phase of inflammation was found to be 38.7,

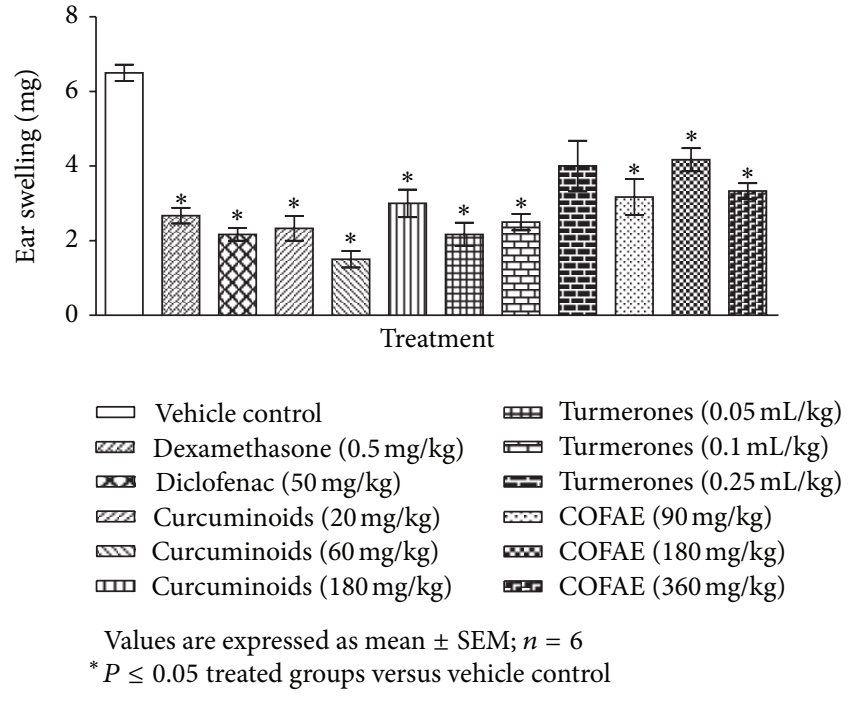

Figure 1: Effect of curcuminoids, turmerones, and COFAE on xylene-induced ear edema in mice.

TABle 1: Percentage inhibition of xylene-induced ear edema by curcuminoids, turmerones, and COFAE.

\begin{tabular}{lc}
\hline Treatment & Inhibition (\%) \\
\hline Vehicle control & 0 \\
Dexamethasone $(0.5 \mathrm{mg} / \mathrm{kg})$ & 58.9 \\
Diclofenac $(50 \mathrm{mg} / \mathrm{kg})$ & 66.6 \\
Curcuminoids $(20 \mathrm{mg} / \mathrm{kg})$ & 64.1 \\
Curcuminoids $(60 \mathrm{mg} / \mathrm{kg})$ & 76.9 \\
Curcuminoids $(180 \mathrm{mg} / \mathrm{kg})$ & 53.8 \\
Turmerones $(0.05 \mathrm{~mL} / \mathrm{kg})$ & 66.6 \\
Turmerones $(0.1 \mathrm{~mL} / \mathrm{kg})$ & 61.5 \\
Turmerones $(0.25 \mathrm{~mL} / \mathrm{kg})$ & 38.4 \\
COFAE $(90 \mathrm{mg} / \mathrm{kg})$ & 51.2 \\
COFAE $(180 \mathrm{mg} / \mathrm{kg})$ & 35.8 \\
COFAE $(360 \mathrm{mg} / \mathrm{kg})$ & 48.7 \\
\hline
\end{tabular}

34.1, and 32.1, respectively. The curcuminoids at 5, 25, and $125 \mathrm{mg} / \mathrm{kg}$ and turmerones at $0.05,0.1$, and $0.15 \mathrm{~mL} / \mathrm{kg}$ dose levels also revealed significant reduction in wet as well as dry weights of the cotton pellets, as compared to the vehicle control.

\section{Discussion}

Complementary and alternative medicine (CAM) for the treatment of various diseases is gaining popularity globally, at a faster pace since the past two decades [26, 27] and the studies revealed a worldwide market for herbal supplements for the management of inflammatory dysfunction/diseases, which is presently at around $83 \%$ and is expected to reach $95 \%$ in the forthcoming years $[28,29]$. In Ayurveda (a type of CAM), Curcuma has a long history of use as an anti-inflammatory agent [30] and has been scientifically 
TABLE 2: Effect of curcuminoids, turmerones, and COFAE on cotton pellet-induced granuloma in rats.

\begin{tabular}{|c|c|c|c|c|}
\hline & Weight of cotton pellets (mg) (wet) & Inhibition (\%) & Weight of cotton pellets (mg) (dry) & Inhibition (\%) \\
\hline Vehicle control $(10 \mathrm{~mL} / \mathrm{kg})$ & $228.6 \pm 7.5$ & 0 & $51.9 \pm 1.1$ & 0 \\
\hline Dexamethasone $(0.5 \mathrm{mg} / \mathrm{kg})$ & $101.2 \pm 5.7^{*}$ & 55.7 & $22.7 \pm 1.9^{*}$ & 56.2 \\
\hline Diclofenac $(5 \mathrm{mg} / \mathrm{kg})$ & $111.0 \pm 10.4^{*}$ & 51.4 & $28 \pm 1.7^{*}$ & 46.0 \\
\hline Curcuminoids ( $5 \mathrm{mg} / \mathrm{kg}$ ) & $143.2 \pm 7.4^{*}$ & 37.3 & $32 \pm 2.0^{*}$ & 38.3 \\
\hline Curcuminoids (25 mg/kg) & $127.5 \pm 12.4^{*}$ & 44.2 & $31.4 \pm 0.6^{*}$ & 39.4 \\
\hline Curcuminoids (125 mg/kg) & $132.9 \pm 9.6^{*}$ & 41.8 & $34.7 \pm 1.2^{*}$ & 33.1 \\
\hline Turmerones $(0.05 \mathrm{~mL} / \mathrm{kg})$ & $140.1 \pm 13.5^{*}$ & 38.7 & $34.5 \pm 1.9^{*}$ & 33.5 \\
\hline Turmerones $(0.1 \mathrm{~mL} / \mathrm{kg})$ & $129.0 \pm 3.7^{*}$ & 43.5 & $33.0 \pm 1.0^{*}$ & 36.2 \\
\hline Turmerones $(0.15 \mathrm{~mL} / \mathrm{kg})$ & $142.7 \pm 8.6^{*}$ & 37.5 & $33.0 \pm 0.7^{*}$ & 36.2 \\
\hline COFAE (45 mg/kg) & $127.4 \pm 4.7^{*}$ & 44.2 & $31.7 \pm 1.7^{*}$ & 38.7 \\
\hline COFAE $(90 \mathrm{mg} / \mathrm{kg})$ & $131.0 \pm 6.6^{*}$ & 42.6 & $34.1 \pm 0.9^{*}$ & 34.1 \\
\hline COFAE $(180 \mathrm{mg} / \mathrm{kg})$ & $144.2 \pm 4.8^{*}$ & 36.9 & $35.2 \pm 1.3^{*}$ & 32.1 \\
\hline
\end{tabular}

Values are expressed as mean $\pm \mathrm{SEM} ; n=6 ;{ }^{*} P \leq 0.05$ treated groups versus vehicle control.

validated extensively. However, curcuminoid and oil-free aqueous extract of $C$. longa have not been yet explored for the anti-inflammatory potential and hence the present study was designed to evaluate the anti-inflammatory activity of COFAE of C. longa in suitable in vivo models to explore biological activity of the extract for use. Furthermore, the effect of COFAE of C. longa was compared with that of curcuminoids and turmerones, the bioactive components of C. longa that are already proven for the anti-inflammatory potential.

Inflammation constitutes body's response to injury and is characterized by a series of events that mainly occur in three distinct phases. The first phase is caused by an increase in vascular permeability resulting in exudation of fluids from the blood into the interstitial space; the second phase involves the infiltration of leukocytes from the blood into the tissue and third phase is characterized by granuloma formation and tissue repair [31]. Therefore, it is vital to estimate the activities of the test substance in different phases of inflammation, while evaluating the anti-inflammatory effect. Accordingly, COFAE of C. longa was investigated for anti-inflammatory potential using acute exudative (xyleneinduced ear edema) and chronic proliferative (cotton pellet granuloma) inflammation models [32-36].

Xylene-induced ear edema model is useful for the evaluation of anti-inflammatory topical steroids and nonsteroidal antiphlogistic agents, especially those inhibiting phospholipase $A_{2}$ [37]. Application of xylene induces acute neurogenous edema, which is partially associated with the substance P. Substance P is widely distributed in the central and peripheral nervous system and its release from sensory neurons in the periphery causes vasodilatation and plasma extravasations leading to swelling of the ear, suggesting the role of xylene in neurogenous inflammation [38]. Moreover, the ear edema associated with xylene involves inflammatory mediators such as histamine, kinin, and fibrinolysin [39]. The COFAE of $C$. longa in the present study exhibited significant activity to counter the acute inflammation in the xyleneinduced ear edema and the effect was comparable to that of curcuminoids and turmerones. The significant inhibition of xylene-induced ear swelling in mice treated with COFAE of $C$. longa provides a probability that the active principles in the extract could reduce the release of substance P or other inflammatory mediators such as histamine, kinin and fibrinolysin or antagonize the actions.

Chronic inflammation is the reaction arising when the acute response is insufficient to eliminate the proinflammatory agents. Chronic inflammation includes proliferation of fibroblasts and infiltration of neutrophils with exudation of fluid. It occurs by means of development of proliferative cells which can either spread or form granuloma [40]. Cotton pellet granuloma model has been widely used to evaluate the transudative, exudative, and proliferative components of chronic inflammation. Transudate phase causes increase in the wet weight of the cotton pellet while hosting inflammatory response to the implanted cotton pellet between 3 and 6 days causes granuloma formation. Therefore, increase in dry weight is considered as a measure of proliferative component of inflammation [41-43].

In the present study, the wet and the dry weights of the pellets, which correlate with transudative and proliferative (granuloma tissue) components of inflammation, were significantly inhibited by COFAE of Curcuma and the effect was equivalent to that of curcuminoids and turmerones. Nevertheless, turmerones showed marginally less anti-inflammatory activity compared to curcuminoids. This reduction in transudate and granuloma formation by COFAE of C. longa administration may be correlated with its ability to reduce the number of fibroblasts and the synthesis of collagen and mucopolysaccharides that are involved in the formation of granuloma tissue [44-46].

C. longa comprises a group of three curcuminoids such as curcumin (diferuloylmethane), demethoxycurcumin, and bisdemethoxycurcumin, as well as volatile oils (turmerone, atlantone, and zingiberene), sugars, proteins, and resins [17]. Yegnanarayan et al. [47] demonstrated significant anti-inflammatory effect of $C$. longa extracts obtained by petroleum ether, $50 \%$ alcohol, and water in both exudative 
and proliferative inflammation. Subsequently, the extensive research on C. longa and curcuminoids specifically on curcumin in the past two decades thoroughly established their anti-inflammatory potential and are reported to downregulate the activity of cyclooxygenase-2 (COX-2), lipoxygenase, and inducible nitric oxide synthase (iNOS) enzymes; inhibit the production of the inflammatory cytokines tumor necrosis factor-alpha (TNF- $\alpha$ ), interleukins (IL) 1, 2, 6, 8 , and 12 , monocyte chemoattractant protein (MCP), and migration inhibitory protein; and downregulate mitogenactivated and Janus kinases [17, 48, 49]. Likewise, Funk et al. and Liju et al. have elucidated the anti-inflammatory effects of turmeric essential oils on acute and chronic inflammatory models and suggested an inhibitory effect on release of inflammatory mediators such as histamine, bradykinin, 5-hydroxytryptamine, and prostaglandins as the mode of action. The present study clearly reinstated the antiinflammatory potential of curcuminoids and turmerones in both acute and chronic inflammatory models.

Curcuminoids and turmerones are usually used for medicinal as well as cosmetic purposes and indeed the COFAE of turmeric is often not used in the preparation of turmeric formulations. Consequently, the present study on COFAE of $C$. longa revealed significant anti-inflammatory potential in both acute exudative and chronic proliferative inflammation models, signifying the presence of bioactive principles in the extract, capable of producing the antiinflammatory effect.

The whole C. longa extract encompasses curcuminoids, volatile oils, and water soluble polysaccharides [50]. However, very few pharmacological studies are available regarding the polysaccharides of Curcuma species. A group of polysaccharides isolated from C. longa, named ukonan A, B, C, and D, have shown reticuloendothelial system-potentiating activity and anticomplementary activities [51]. Polysaccharides isolated from related species C. zedoaria and C. xanthorrhiza have been shown to have macrophage-stimulating activity via specific activation of NF- $\kappa \mathrm{B}[52,53]$. Moreover, recent reports available on polysaccharides from different natural sources indicated their role as free radical scavengers and antioxidants, which has been suggested as the pharmacological basis for prevention of inflammation and atherosclerosis by polysaccharides [54]. Also clinical trial by Madhu et al., [55] that evaluated the efficacy of Curcuma longa containing polysaccharides in osteoarthritis patients, indicates the involvement of polysaccharides against inflammation [55]. Hence, the anti-inflammatory effect obtained after COFAE of $C$. longa treatment could be correlated with the presence of polysaccharides and/or any other unexplored active principles. Consequently, there is a definite need for detailed experimental studies to define the precise mechanism of action of COFAE of C. longa and to have an elaborative phytochemical study to elucidate the active molecule(s) responsible for the therapeutic effect.

In conclusion, the present study demonstrated potent anti-inflammatory activity of COFAE of C. longa, even comparable to that of the proven anti-inflammatory bioactive components of Curcuma, namely, curcuminoids and turmerones, in both acute exudative (xylene induced ear edema) and chronic proliferative (cotton pellet granuloma) inflammation models, thereby indicating the possibility of developing COFAE of C. longa as a safe and potent antiinflammatory substance.

\section{Conflict of Interests}

The authors declare that they have no conflict of interests to disclose.

\section{References}

[1] G. Egger, "In search of a germ theory equivalent for chronic disease," Preventing Chronic Disease, vol. 9, pp. 1-7, 2012.

[2] Y. Mizuno, R. F. Jacob, and R. Preston Mason, "Inflammation and the development of atherosclerosis-effects of lipidlowering therapy," Journal of Atherosclerosis and Thrombosis, vol. 18, no. 5, pp. 351-358, 2011.

[3] CIHR Canadian Institutes of Health Research, "Inflammation in chronic disease initiative," 2012, http://www.cihr-irsc .gc.ca/e/44070.html.

[4] S. Su, T. Wang, J.-A. Duan et al., "Anti-inflammatory and analgesic activity of different extracts of Commiphora myrrha," Journal of Ethnopharmacology, vol. 134, no. 2, pp. 251-258, 2011.

[5] L. Laine, R. Smith, K. Min, C. Chen, and R. W. Dubois, "Systematic review: the lower gastrointestinal adverse effects of nonsteroidal anti-inflammatory drugs," Alimentary Pharmacology and Therapeutics, vol. 24, no. 5, pp. 751-767, 2006.

[6] L. Rodrigo, R. De Francisco, J. M. Pérez-Pariente et al., "Nimesulide-induced severe hemolytic anemia and acute liver failure leading to liver transplantation," Scandinavian Journal of Gastroenterology, vol. 37, no. 11, pp. 1341-1343, 2002.

[7] H. Tag, A. K. Das, and H. Loyi, "Anti-inflammatory plants used by the Khamti tribe of Lohit district in eastern Arunachal Pradesh, India," Natural Product Radiance, vol. 6, no. 4, pp. 334340, 2007.

[8] R. McCaleb, E. Leigh, and K. Morien, "Turmeric, Curcuma longa, Zingiberaceae," in The Encyclopedia of Popular Herbs, pp. 374-381, CA: Prima Publishing, 2000.

[9] G. K. Jayaprakasha, L. Jagan Mohan Rao, and K. K. Sakariah, "Chemistry and biological activities of C. longa," Trends in Food Science and Technology, vol. 16, no. 12, pp. 533-548, 2005.

[10] P. T. Trinidad, S. S. Rosario, P. D. L. Marco, C. M. Aida, and P. B. Melissa, "Zingiber officinale and Curcuma longa as potential functional foods/ingredients," Food and Public Health, vol. 2, no. 2, pp. 1-4, 2012.

[11] O. P. Sharma, "Antioxidant activity of curcumin and related compounds," Biochemical Pharmacology, vol. 25, no. 15, pp. 1811-1812, 1976.

[12] P. S. Negi, G. K. Jayaprakasha, L. J. M. Rao, and K. K. Sakariah, "Antibacterial activity of turmeric oil: a byproduct from curcumin manufacture," Journal of Agricultural and Food Chemistry, vol. 47, no. 10, pp. 4297-4300, 1999.

[13] J. L. Funk, J. B. Frye, J. N. Oyarzo, H. Zhang, and B. N. Timmermann, "Anti-arthritic effects and toxicity of the essential oils of turmeric (Curcuma longa L.)," Journal of Agricultural and Food Chemistry, vol. 58, no. 2, pp. 842-849, 2010.

[14] B. B. Aggarwal, A. Kumar, and A. C. Bharti, "Anticancer potential of curcumin: preclinical and clinical studies," Anticancer Research, vol. 23, no. 1, pp. 363-398, 2003. 
[15] The Ayurvedic Pharmacopoeia of India by Ministry of Health \& Family Welfare, Govt. of India, vol.1, 2001.

[16] S. Wu and Y. S. Guan, Chinese Pharmacopoeia Commission, Chinese Pharmacopoeia, 2010.

[17] J. S. Jurenka, "Anti-inflammatory properties of curcumin, a major constituent of Curcuma longa: a review of preclinical and clinical research," Alternative Medicine Review, vol. 14, no. 2, pp. 141-153, 2009.

[18] M. B. Patil, S. V. Taralkar, V. S. Sakpal, S. P. Shewale, and R. S. Sakpal, "Extraction, isolation and evaluation of antiinflammatory activity of Curcuminoids from Curcuma longa," International Journal of Chemical Sciences and Applications, vol. 2, no. 3, pp. 172-174, 2011.

[19] V. B. Liju, K. Jeena, and R. Kuttan, "An evaluation of antioxidant, anti-inflammatory, and antinociceptive activities of essential oil from Curcuma longa L.," Indian Journal of Pharmacology, vol. 43 , no. 5, pp. 526-531, 2011.

[20] G. G. L. Yue, B. C. L. Chan, P.-M. Hon et al., "Evaluation of in vitro anti-proliferative and immunomodulatory activities of compounds isolated from Curcuma longa," Food and Chemical Toxicology, vol. 48, no. 8-9, pp. 2011-2020, 2010.

[21] S. S. Deshpande, A. D. Ingle, and G. B. Maru, "Chemopreventive efficacy of curcumin-free aqueous turmeric extract in 7,12dimethylbenz $[\alpha]$ anthracene-induced rat mammary tumorigenesis," Cancer Letters, vol. 123, no. 1, pp. 35-40, 1998.

[22] M. A. Azuine, J. J. Kayal, and S. V. Bhide, "Protective role of aqueous turmeric extract against mutagenicity of direct-acting carcinogens as well as benzo $[\alpha]$ pyrene-induced genotoxicity and carcinogenicity," Journal of Cancer Research and Clinical Oncology, vol. 118, no. 6, pp. 447-452, 1992.

[23] G. Suresh Kumar, A. K. Shetty, and P. V. Salimath, "Modulatory effect of fenugreek seed mucilage and spent turmeric on intestinal and renal disaccharidases in streptozotocin induced diabetic rats," Plant Foods for Human Nutrition, vol. 60, no. 2, pp. 87-91, 2005.

[24] A. H. Atta and A. Alkofahi, "Anti-nociceptive and antiinflammatory effects of some Jordanian medicinal plant extracts," Journal of Ethnopharmacology, vol. 60, no. 2, pp. 117$124,1998$.

[25] P. F. D’Arcy, E. M. Howard, P. W. Mugg leton, and S. B. Townsend, "The anti-inflammatory action of griseofulvin in experimental animals," Journal of Pharmacy and Pharmacology, vol. 12, no. 1, pp. 659-665, 1960.

[26] D. M. Eisenberg, R. B. Davis, S. L. Ettner et al., "Trends in alternative medicine use in the United States, 1990-1997: results of a follow-up national survey," Journal of the American Medical Association, vol. 280, no. 18, pp. 1569-1575, 1998.

[27] "The use of complementary and alternative medicine in the united states," National Center for Complementary and Alternative Medicine, 2012, http://nccam.nih.gov/news/camstats/ 2007/camsurvey_fs1.htm.

[28] "Program profile: international liaison brings global vision to OAM," Complementary and Alternative Medicine at the NIH, vol. 3, pp. 3-10, 1996.

[29] S. Beg, S. Swain, H. Hasan, M. A. Barkat, and M. S. Hussain, "Systematic review of herbals as potential anti-inflammatory agents: recent advances, current clinical status and future perspectives," Pharmacognosy Reviews, vol. 5, no. 10, pp. 120-137, 2011.

[30] EMEA European Medicines Agency, "Assessment re-port on Curcuma longa L. Rhizoma Doc," Tech. Rep. EMEA/ HMPC/456848/2009, 2009.
[31] V. B. Badgujar, P. S. Jain, R. R. Patil, N. G. Haswani, and S. G. Chaudhari, "Anti-inflammatory activity of Helicteres isora L. stem bark extracts in rats," Asian Journal of Pharmaceutical and Clinical Research, vol. 2, pp. 63-65, 2009.

[32] I. Igbe, F. P. Ching, and A. Eromon, "Anti-inflammatory activity of aqueous fruit pulp extract of Hunteria umbellata K. schum in acute and chronic inflammation," Acta Poloniae Pharmaceutica, vol. 67 , no. 1, pp. 81-85, 2010.

[33] R. I. Udegbunam, U. I. Asuzu, R. O. C. Kene, S. O. Udegbunam, and C. Nwaehujor, "Anti-nociceptive, anti-inflammatory and anti-oxidant effects of the methanol leaf extract of sterculia tragacantha lindl," Journal of Pharmacology and Toxicology, vol. 12, no. 6, pp. 516-524, 2011.

[34] V. Elango, O. Carolin, and P. S. Raghu, "Anti-inflammatory activity of the flower extracts of Solanum nigrum in Rats," Hygeia Journal For Drugs and Medicines, vol. 4, no. 1, pp. 5962, 2012.

[35] A. Eidi, M. Eidi, V. Mozaffanan et al., "Antinociceptive and antiinflammatory effects of ethanolic extract of Salvia syriaca L. in mice," International Journal of Pharmacology, vol. 7, no. 3, pp. 394-399, 2011.

[36] H. Hosseinzadeh and H. M. Younesi, "Antinociceptive and anti-inflammatory effects of Crocus sativus L. stigma and petal extracts in mice," BMC Pharmacology, vol. 2, article 7, 2002.

[37] J. C. Zanini Jr., Y. S. Medeiros, A. B. Cruz, R. R. A. Yunes, and J. B. Calixto, "Action of compounds from Mandevilla velutina on croton oil-induced ear oedema in mice. A comparative study with steroidal and nonsteroidal antiinflammatory drugs," Phytotherapy Research, vol. 6, no. 1, pp. 1-5, 1992.

[38] J. D. Richardson and M. R. Vasko, "Cellular mechanisms of neurogenic inflammation," Journal of Pharmacology and Experimental Therapeutics, vol. 302, no. 3, pp. 839-845, 2002.

[39] R. P. Carlson, L. O’Neill-Davis, J. Chang, and A. J. Lewis, “Modulation of mouse ear edema by cyclooxygenase and lipoxygenase inhibitors and other pharmacologic agents," Agents and Actions, vol. 17, no. 2, pp. 197-204, 1985.

[40] M. Gupta, U. Mazumder, S. K. Ramanathan, and S. K. Thangavel, "Studies on anti-inflammatory, analgesic and antipyretic properties of methanol extract of Caesalpinia bonducella leaves in experimental animal models," Iranian Journal of Pharmacology and Therapeutics, vol. 2, no. 2, pp. 30-34, 2003.

[41] R. K. N. Cuman, C. A. Bersani-Amado, and Z. B. Fortes, "Influence of type 2 diabetes on the inflammatory response in rats," Inflammation Research, vol. 50, no. 9, pp. 460-465, 2001.

[42] K. F. Swingle and F. E. Shideman, "Phases of the inflammatory response to subcutaneous implantation of a cotton pellet and their modification by certain anti-inflammatory agents," Journal of Pharmacology and Experimental Therapeutics, vol. 183, no. 1, pp. 226-234, 1972.

[43] S. S. Kumar, T. Sivakumar, M. J. Chandrasekar, and B. Suresh, "Evaluation of anti-inflammatory activity of Eclipta alba in rats," Ancient Science of Life, vol. 24, no. 3, pp. 112-118, 2005.

[44] C. V. Chandrasekaran, K. Sundarajan, J. R. Edwin, G. M. Gururaja, D. Mundkinajeddu, and A. Agarwal, "Immunestimulatory and anti-inflammatory activities of Curcuma longa extract and its polysaccharide fraction," Pharmacognosy Research, vol. 5, no. 2, pp. 71-79, 2013.

[45] R. D. Granstein, M. R. Deak, S. L. Jacques et al., “The systemic administration of gamma interferon inhibits collagen synthesis and acute inflammation in a murine skin wounding model," Journal of Investigative Dermatology, vol. 93, no. 1, pp. 18-27, 1989. 
[46] A. Mallat, A.-M. Preaux, S. Blazejewski, J. Rosenbaum, D. Dhumeaux, and P. Mavier, "Interferon alfa and gamma inhibit proliferation and collagen synthesis of human Ito cells in culture," Hepatology, vol. 21, no. 4, pp. 1003-1010, 1995.

[47] R. Yegnanarayan, A. P. Saraf, and J. H. Balwani, "Comparison of anti inflammatory activity of various extracts of Curcuma longa (Linn)," Indian Journal of Medical Research, vol. 64, no. 4, pp. 601-608, 1976.

[48] Y. Abe, S. Hashimoto, and T. Horie, "Curcumin inhibition of inflammatory cytokine production by human peripheral blood monocytes and alveolar macrophages," Pharmacological Research, vol. 39, no. 1, pp. 41-47, 1999.

[49] M. Schaffer, P. M. Schaffer, J. Zidan, and G. B. Sela, "Curcuma as a functional food in the control of cancer and inflammation," Current Opinion in Clinical Nutrition and Metabolic Care, vol. 14, no. 6, pp. 588-597, 2011.

[50] G. G. L. Yue, B. C. L. Chan, P.-M. Hon et al., "Immunostimulatory activities of polysaccharide extract isolated from Curcuma longa," International Journal of Biological Macromolecules, vol. 47, no. 3, pp. 342-347, 2010.

[51] R. Gonda, K. Takeda, N. Shimizu, and M. Tomoda, "Characterization of a neutral polysaccharide having activity on the reticuloendothelial system from the rhizome of Curcuma longa," Chemical and Pharmaceutical Bulletin, vol. 40, no. 1, pp. 185-188, 1992.

[52] K. I. Kim, K. S. Shin, W. J. Jun et al., "Effects of polysaccharides from rhizomes of Curcuma zedoaria on macrophage functions," Bioscience, Biotechnology and Biochemistry, vol. 65, no. 11, pp. 2369-2377, 2001.

[53] A.-J. Kim, Y.-O. Kim, J.-S. Shim, and J.-K. Hwang, "Immunostimulating activity of crude polysaccharide extract isolated from Curcuma xanthorrhiza Roxb," Bioscience, Biotechnology and Biochemistry, vol. 71, no. 6, pp. 1428-1438, 2007.

[54] H. Wang, X. Zhang, and C. Fusheng, "Antioxidant activity of bioactive polysaccharides isolated from natural sources," Journal of Animal Science and Biotechnology, vol. 2, no. 4, pp. 230-238, 2011.

[55] K. Madhu, K. Chanda, and M. J. Saji, "Safety and efficacy of Curcuma longa extract in the treatment of painful knee osteoarthritis: a randomized placebo-controlled trial," Inflammopharmacology, vol. 21, no. 2, pp. 129-362, 2013. 

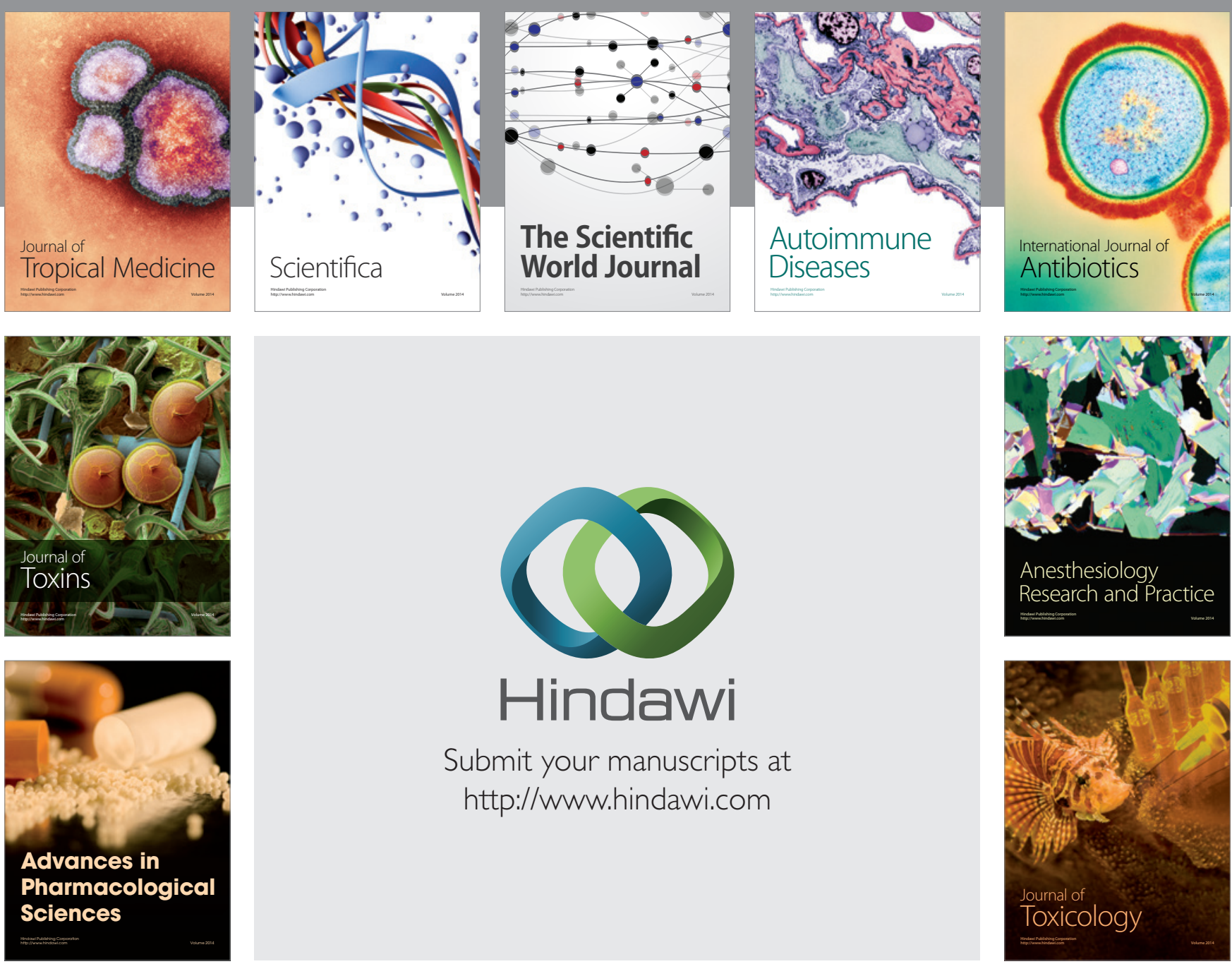

\section{Hindawi}

Submit your manuscripts at

http://www.hindawi.com
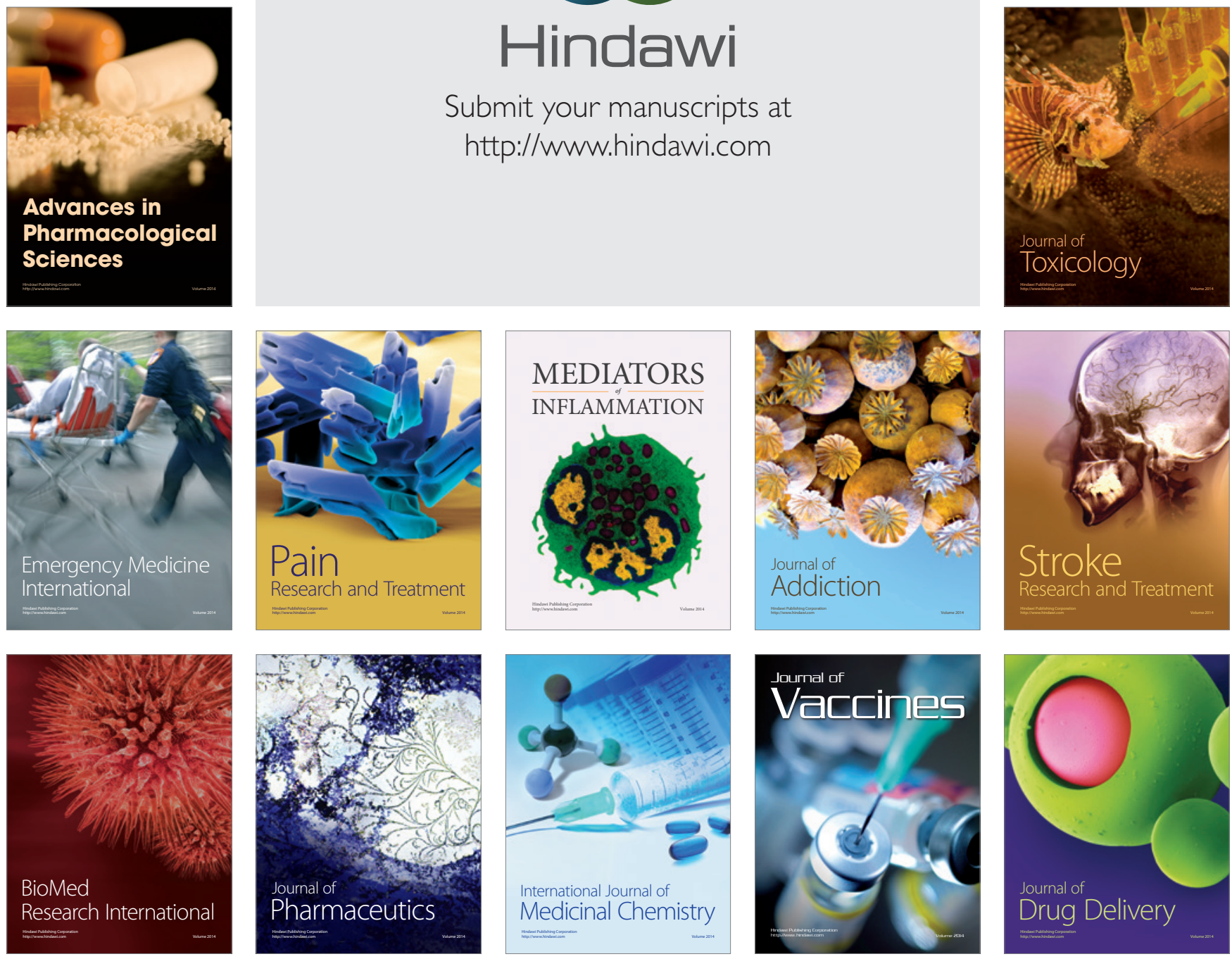